\title{
EVALUATING THE IMPACT OF THE COMPONENTS OF A MOBILE BEHAVIOR CHANGE INTERVENTION TO SUPPORT CRITICAL THINKING IN RESEARCH PROJECTS
}

\author{
Yousef Asiri, David Millard and Mark Weal \\ University of Southampton, Department of Electronics and Computer Science, Faculty of Engineering and Physical \\ Sciences, SO17 1BJ, Southampton, United Kingdom
}

\begin{abstract}
This paper presents a study which aims to provide an understanding of the impact of using the components of a digital mobile-based behavior change intervention $(\mathrm{mBCI})$ to support critical thinking skills during university student research projects. The digital behavior change interventions are tools and techniques designed to induce behavior change and provide continuous support and tailored advice for willing learners through web and mobile platforms. We investigated the impact and the usability of the designed tools by analyzing self-reflections and the users on the digital mobile-based behavior change intervention components. An instrument was used to examine the differences in the self-perceived improvement of critical thinking between the intervention group and the control group before and after working on real research projects for two months. The results of comparing post surveys for the independent samples showed that the intervention group had a statistically significant perceived improvement in critical thinking than the control group. The findings indicated encouraging and positive feedback on the use of mobile intervention components to promote critical thinking when supervising research projects.
\end{abstract}

\section{KEYWORDS}

Critical Thinking, Digital Intervention, Mobile Learning

\section{INTRODUCTION}

Critical thinking is an essential tool for students to be able to reasonably analyze, understand and evaluate arguments in their research projects (Carpi et al., 2017; Yilmaz and Keser, 2016). Research projects are research-based tasks that enable learners to study a specific problem by examining the possible solutions to be supported with reliable evidence (Devi et al., 2017). Students are usually supervised throughout their research projects. According to Ismail et al. (2017) and Clear et al. (2014), traditional face-to-face meetings are commonly used to facilitate communication between students and their supervisors. Technology has been used to partly overcome the communication barriers of time and place (Seifi et al., 2014). Critical thinking, however, is important to be individually supported in research projects and individually tailored to students' levels of critical thinking (Brew and Mantai 2017; Duron et al., 2006). Delivering scalable critical thinking content with relevant advice to students during their research projects through technical tools must be compatible with the nature of critical thinking (Haghparast et al., 2014). It is necessary to design appropriate tools to assist both students and supervisors to enrich the individual learning experience when critical thinking is considered. A few research gaps have been identified in using technology in critical thinking, and these deficiencies could be the cause of the lack of critical thinking. First, there are inconsistencies in definitions to comprehensively cover critical thinking, not only as a skill but also as a lifelong behavior that requires sufficient time to accumulate (Al-Mubaid and Bettayeb, 2017; Paul and Elder, 2013). Second, there has also been little research in dealing with critical thinking and research projects together as relatively associated tasks (Brew and Mantai 2017; Yilmaz and Keser, 2016). Finally, there is a lack of well-tested suitable tools to help academic supervisors, who may lack the technical knowledge to create mobile or web-based interventions to evaluate students' progress and behavior in critical thinking. In fact, the available tools provide mostly manual settings; 
once they are developed, they are relatively fixed and inflexible, unable for large-scale reuse or iteratively collect randomized data (Swart, 2017; Seifi et al., 2014).

We suggest that using digital mobile behavioral change intervention $(\mathrm{mBCI})$ methods could provide a convenient technical tool to assist students to develop critical thinking and research skills. As argued by Wai et al. (2018) and Saade (2012), associating critical thinking with behavior provides an insight into the potential success of linking mobile devices to learners with fewer restrictions in time and place. Smart-phones that provide interventions could help students improve their critical thinking behaviors during their research work (Asiri et al., 2017; Wilde and Zaluska, 2016). This research will study the impact of using a mobile application, subdivided down to its components, to encourage behavioral changes to improve critical thinking for third-year students in their research projects before and after the intervention. The identified mobile components used in this study are: 1) activities and training for leaners to understand critical thinking, 2) tasks for practicing critical thinking, 3) a basic information page about the research project of the learner, 4) short questionnaires to examine the progress of critical thinking, 5) goals and plans settings, 6) notifications for nudges and triggers to keep learners engaged in the mobile intervention, 7) inquiries by the learners, and lastly 8) providing answers and feedback by the researcher to support critical thinking. The components were identified based on a literature review and previous interviews with supervisors and academics; published recently by the same authors of this paper. The existing LifeGuide Toolbox software, co-designed by the authors, has the potential to be successful in designing mobile intervention components to promote critical thinking. The LifeGuide Toolbox software package consists of an authoring tool that enables intervention builders with minimal programming background to easily create mobile interventions with the mentioned components. As a result, the tool could be widely used by many researchers to provide them with the data that they need about students' behaviors regarding their critical thinking in research projects. The suggestions provided by the components of the mobile intervention, provide students with relevant information and regular advice to improve their behaviors toward their critical thinking during their research projects.

\section{BACKGROUND}

Within the context of mobile learning, smartphones are suggested to offer superior online learning content because of their unique personalization features, flexibility, connectedness, and portability (Wai et al., 2018). Mobile technology is one of the most important innovations affecting almost everything in our lives, from personal interaction and social communication to education and work. Critical thinking, from this perspective, is also an essential daily activity that could be encouraged by mobile technology (Asiri et al., 2017). Attaching critical thinking to the daily use of mobile devices could help students monitor decision-making, change behaviors, acquire intervention support, and track thinking patterns through their diaries, reminders and goals at any time and from anywhere. Several attempts have been made to use mobile technology to promote learning and thinking skills in different educational settings. For instance, Alnuaim et al. (2014) examined the impact of a contextual mobile learning application to improve students' design thinking through collaboration between learners. Similarly, Wong (2013) designed and used a mobile critique platform that enables and motivates designers to co-design with each other and criticize each other's work. However, generally the results of using mobile technology to improve critical thinking for students indicated that students still have low levels of critical thinking ability, as addressed by Yilmaz and Keser (2016). Moreover, mobile technology has not been used to promote critical thinking in the context of research projects by enabling supervisors with less programming background to use tested flexible tools to create and deliver reusable digital mobile-based interventions to their students. These deficiencies were resolved in the current study.

\subsection{Digital Behavior Change Interventions (DBCIs)}

Digital behavior change interventions are techniques used to provide continuous tailored advice for learners wishing to improve their behavior through web and mobile platforms (Yardley et al. 2016). Digital intervention has been used in health education fields to facilitate communication between doctors and patients. Data generated from the web-based or mobile-based tools can be studied by evaluating how both experts and users interact with the system, when and how the information is delivered to the users, and by identifying behaviors patterns (Hargood et al. 2014). As mentioned earlier, the features in the LifeGuide Toolbox software are 
suitable for study because they flexibly provide cross-platform applications for critical thinking cases. The software contains several components that can be broken down for this study such as designing activities, tasks, short quizzes, planner, goal setting, sending notifications, and receiving questions from intervention users. According to Lustria et al. (2013), a digital behavior change intervention involves three main interacting participants, as illustrated in Fig. 1. First, the intervention developers (i.e. programmers) provide the necessary tools for digital interactions between intervention experts and users through web or mobile platforms. Second, the intervention experts (i.e. researchers) who may lack sufficient programming skills but may still design digital interventions for their users. Third, the intervention users who are the targets of intervention from the experts, may then pass data back to the experts by using the mobile-based or web-based intervention that then permits an iterative improvement of the intervention.

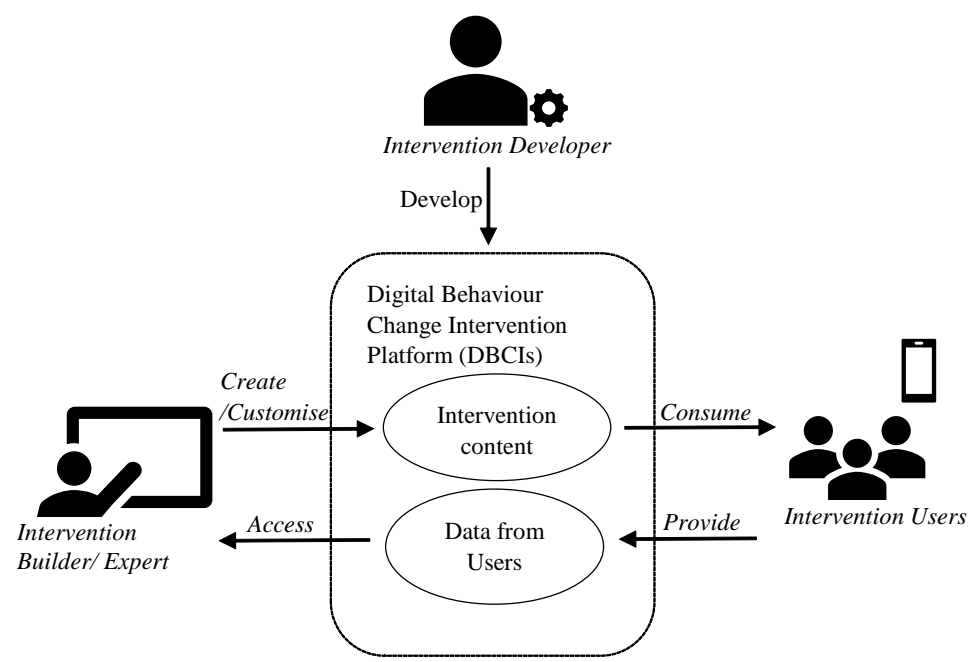

Figure 1. Main Actors in Digital Behavior Change Interventions (DBCIs)

The use of DBCI systems in blended educational contexts can influence higher education in a variety of ways. Firstly, for students, the systems can influence their approaches to learning and may stimulate communication with their educators or with each other. Secondly, for educators, DBCIs may assist the development and selection of online resources and change traditional teaching practices. Thirdly, for institutions and researchers, DBCIs can provide large data sets that can be analyzed to investigate more deeply the processes of learning and learner behavior.

\section{METHODOLOGY}

The study aims to examine the impact of using a mobile application-based behavior change intervention on students' critical thinking in the context of research projects. A mixed method approach was used to collect qualitative and quantitative data from participants. The participants were third-year undergraduate students from the Electronics and Computer Science (ECS) program at the university, who were invited to participate by using the university's 3rd year ECS email list. Sixty students who agreed to participate were divided randomly into two equal groups; a control group and the group that used the mobile application-based intervention for two months. Differences in critical thinking skills before and after the experiment between the two groups were explored.

\subsection{Procedure}

As shown in (Table 1), a validated instrument was used as a pre- and post-survey tool, which was designed by the authors of this paper, to measure critical thinking in research projects in the context of digital behavior change intervention. The instrument was inspired by the Paul-Elder critical thinking framework, which consists of two sections; the Intellectual Standards' statements, and the statements for the Elements of Thought 
(Paul and Elder, 2013). The participants were asked to self-reflect on their critical thinking skills using the instrument based on those statements from the Likert scale: No $=1$, Sometimes $=2$, Not sure $=3$, Usually $=4$, and Always $=5$ using the online iSurvey website forms before and after the experiment. Text boxes were left empty for adding explanations or comments by participants at the end of the pre- and post-online surveys.

Table 1. An Instrument to Assess Critical Thinking in Research Projects for DBCI Context

\begin{tabular}{|c|c|}
\hline Intellectual Standards & Elements of Thought \\
\hline $\begin{array}{l}\text { Clarity: When I write reports or essays, I express my } \\
\text { thinking clearly in different ways and with multiple } \\
\text { supporting examples. } \\
\text { Accuracy: I support my arguments by making sure that } \\
\text { all information is correct and free from errors based on } \\
\text { the reliable resources. } \\
\text { Precision: In writing, my words and data used are } \\
\text { specifically exact and no more details could be added to } \\
\text { explain what I mean. } \\
\text { Significance: I essentially focus in my research work on } \\
\text { the most important ideas and crucial facts that would help } \\
\text { to make a meaningful point. } \\
\text { Relevance: In the literature review, everything included } \\
\text { is important, that each part makes a difference and } \\
\text { accordingly I connect my arguments to any reliable } \\
\text { relevant information. } \\
\text { Depth: My arguments are thorough by tending to explore } \\
\text { the complexities in the research questions which are } \\
\text { addressed profoundly in my answers. } \\
\text { Breadth: I consider additional perspectives and different } \\
\text { viewpoints when I think or write in my research work to } \\
\text { look at the problem from various ways. } \\
\text { Logic: My arguments are reasonable that the thinking is } \\
\text { consistent, and the conclusions follow from the evidence } \\
\text { where things make sense step-by-step. } \\
\text { Fairness: My arguments are balanced, objective and free } \\
\text { from hidden biases by considering both positive and } \\
\text { negative outcomes. }\end{array}$ & $\begin{array}{l}\text { Purpose: I think purposefully when I set my research } \\
\text { objectives by trying to answer what the main goal of my } \\
\text { work is and why it is important. } \\
\text { Questions: I use my research questions as a guidance for } \\
\text { my thinking to figure out how to solve the research } \\
\text { problems. } \\
\text { Information: The information I use is correct, accurate and } \\
\text { relevant to the purpose and to the questions or issues I am } \\
\text { addressing. } \\
\text { Inferences: The inferences and conclusions I make } \\
\text { logically follow from the evidence with no more or less than } \\
\text { what is implied in the situation. } \\
\text { Concepts: I justifiably use concepts, ideas, theories, laws, } \\
\text { principles, or hypotheses in thinking to make sense of things } \\
\text { in my research work. } \\
\text { Assumptions: In assumptions, which are the beliefs I take } \\
\text { for granted subconsciously or unconsciously, I make sure } \\
\text { that they are justified by sound evidence. } \\
\text { Point of view: In my research work, I understand the } \\
\text { limitations of my point of view and I fully consider other } \\
\text { relevant reasonable viewpoints. } \\
\text { Implications: I am aware that the implications of my claims } \\
\text { logically follow from other claims or truths, where } \\
\text { implications follow from thoughts and consequences follow } \\
\text { from actions. }\end{array}$ \\
\hline
\end{tabular}

Once students completed the pre-online survey, another email was sent to invite the intervention group to continue participating in the mobile intervention experiment for two months by downloading a mobile application from the AppStore or Google Play based on their phone's operating systems. The mobile application-based behavior change intervention (Figure 2) was created by the LifeGuide Toolbox software for this experiment. The components of the mobile application are designed to enable users to interact with the content of the intervention. The intervention components used in this experiment are broken down into 1) activities and training for users to understand critical thinking, 2) tasks for users to practice critical thinking, 3) a basic information page about the research project of the users, 4) short questionnaires to examine the progress of critical thinking, 5) goals and plans settings, 6) notifications for nudges and triggers to keep users engaged in the mobile intervention, 7) inquiries by the users, and lastly 8) providing answers and feedback by the researcher to support critical thinking. The content of the critical thinking activities and tasks were formed from two recent books (Cottrell, 2017; Paul and Elder, 2013). During the experiment, participants in the intervention group received mobile notifications from the researcher. The types of notification vary based on the intervention needed to be supported. The intervention components were mapped into the Intellectual Standards and the Elements of Thought to understand which components contributed to enhance certain skills in critical thinking. Collecting data about approximately how much time spent in each component, along with the texts with responses to those components was a way of assessing the impact of the mobile intervention in this research. After finishing the two-month experiment, participants from both groups filled out the post-online survey to examine the differences between the two groups in critical thinking. 

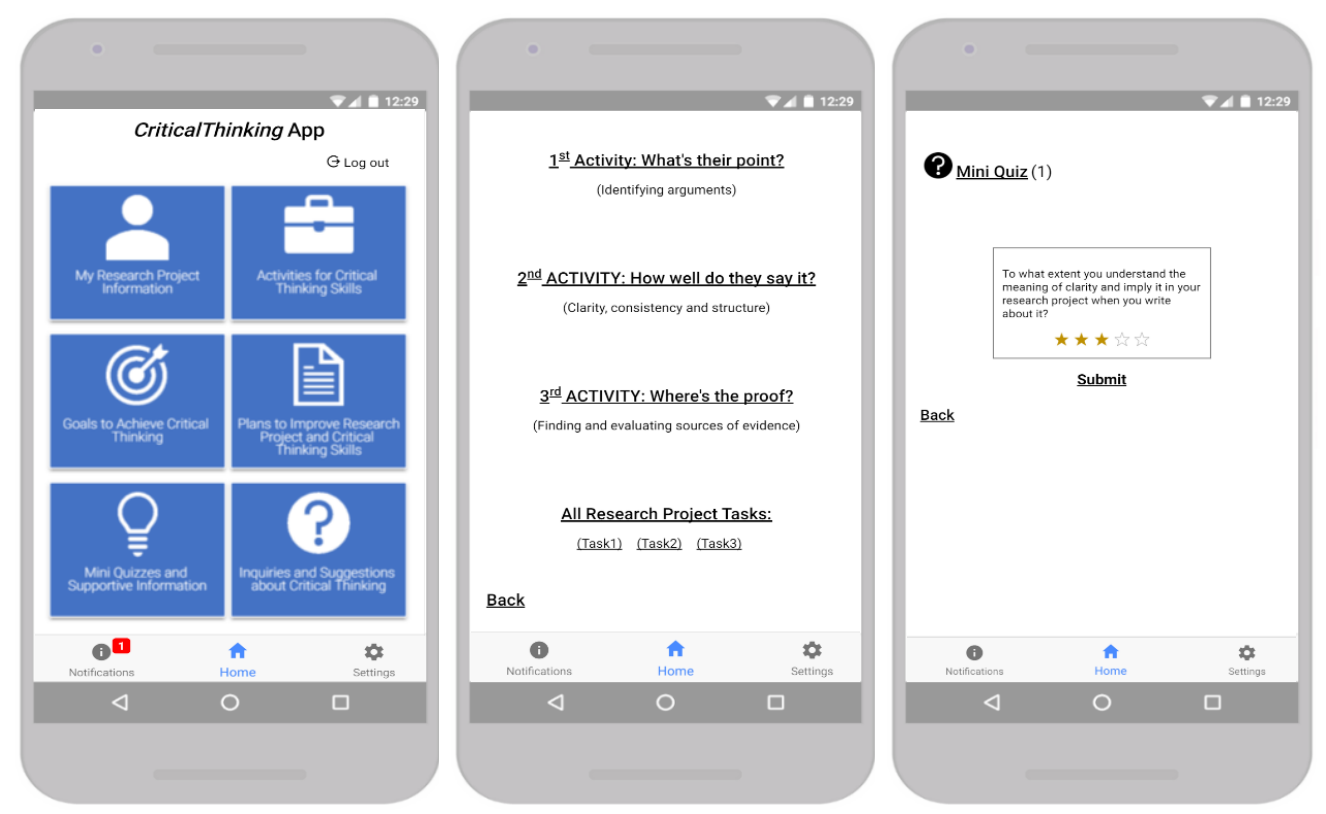

Figure 2. Home Page, Activity Page and Short Quizzes Page in The Mobile Application-based Intervention

\subsection{Data Analysis}

Two main factors in the analysis were used to examine the impact of the components of the digital behavior change intervention on participants' critical thinking and research skills. First, analyzing the data from the pre, post and SUS (Usability of the System) surveys provides evidence for perceived improvements, if any, in the critical thinking Standards and the Elements of thought for both groups and to examine usability. The SUS test consists of ten questions with five response options from strongly agree to strongly disagree, which provides a reliable tool for measuring the system usability (Brooke, 1996). Second, analyzing the data from log files for the mobile application was used to study the correlation between critical thinking improvement and time spent in the mobile application, usage patterns and the level of engagement affected by the mobile notification.

\section{RESULTS AND FINDINGS}

Sixty participants completed both the before and after-online surveys from both intervention and control groups; thirty participants for each group. The results of independent t-tests for comparing between mean values between the two groups in the pre-surveys showed that there were no statistically significant differences (with $\mathrm{p}<0.05$ ) in the Intellectual Standards or the Elements of Thought before the experiment was carried out, with participants from both groups having equivalent perceived levels of critical thinking skills in research projects. However, a paired t-test comparing the post-experimental surveys showed that both groups had significantly improved their critical thinking skills, indicating an increase in some Standards and some Elements regardless of intervention. Table. 1 shows the results of a paired t-test that compares mean values for the pre- and post-experimental surveys within the same participants for the control group. There were statistically significant differences after the experiment (with $\mathrm{p}<0.05$ ) in the Intellectual Standards: Relevance and Logic and in the Elements of Thought: Questions and Information. Similarly, for the intervention group, as shown in Table 2, the paired t-test showed that there were statistically significant differences after the experiment in the Intellectual Standards: Clarity, Relevance, Breadth, and Logic and in the Elements of Thought: Questions, Information and Point of View. 
Table 2. Paired Samples Test for Pre and Post Surveys: Control Group

\begin{tabular}{|c|c|c|c|c|c|c|c|c|}
\hline \multirow{3}{*}{$\begin{array}{l}\text { Intellectual } \\
\text { Standards and } \\
\text { Elements of } \\
\text { Thought }\end{array}$} & \multicolumn{5}{|c|}{ Paired Differences } & \multirow[t]{3}{*}{ t-test } & \multirow[t]{3}{*}{$\overline{\mathrm{df}}$} & \multirow{3}{*}{$\begin{array}{l}\text { Sig. } \\
\text { (2-tailed) }\end{array}$} \\
\hline & \multirow[t]{2}{*}{ Mean } & \multirow[t]{2}{*}{$\begin{array}{l}\text { Std. } \\
\text { Deviation }\end{array}$} & \multirow[t]{2}{*}{$\begin{array}{l}\text { Std. } \\
\text { Error } \\
\text { Mean }\end{array}$} & \multicolumn{2}{|c|}{$\begin{array}{l}95 \% \text { Confidence } \\
\text { Interval of the } \\
\text { Difference }\end{array}$} & & & \\
\hline & & & & Lower & Upper & & & \\
\hline Clarity & -.266 & .980 & .178 & -.632 & .099 & -1.490 & 29 & .147 \\
\hline Accuracy & -.066 & .739 & .135 & -.342 & .209 & -.494 & 29 & .625 \\
\hline Precision & .200 & .610 & .111 & -.027 & .427 & 1.795 & 29 & .083 \\
\hline Relevance & -.700 & 1.441 & .263 & -1.238 & -.161 & -2.659 & 29 & .013 \\
\hline Significance & -.400 & 1.404 & .256 & -.924 & .124 & -1.560 & 29 & .130 \\
\hline Depth & .066 & .739 & .135 & -.209 & .342 & .494 & 29 & .625 \\
\hline Breadth & -.133 & 1.455 & .265 & -.676 & .410 & -.502 & 29 & .620 \\
\hline Logic & -.466 & 1.195 & .218 & -.913 & -.020 & -2.138 & 29 & .041 \\
\hline Fairness & -.333 & .994 & .181 & -.704 & .037 & -1.836 & 29 & .077 \\
\hline Purpose & -.033 & .764 & .139 & -.318 & .252 & -.239 & 29 & .813 \\
\hline Questions & -.433 & 1.135 & .207 & -.857 & -.009 & -2.091 & 29 & .045 \\
\hline Information & -.433 & 1.040 & .189 & -.821 & -.044 & -2.282 & 29 & .030 \\
\hline Inferences & -.266 & 1.048 & .191 & -.658 & .124 & -1.393 & 29 & .174 \\
\hline Concepts & -.066 & 1.172 & .214 & -.504 & .371 & -.311 & 29 & .758 \\
\hline Assumptions & -.300 & 1.489 & .271 & -.856 & .256 & -1.104 & 29 & .279 \\
\hline Point of view & .000 & .787 & .143 & -.294 & .294 & .000 & 29 & 1.00 \\
\hline Implications & -.100 & .994 & .181 & -.471 & .271 & -.551 & 29 & .586 \\
\hline
\end{tabular}

Table 3. Paired Samples Test for Pre and Post Surveys: Intervention Group

\begin{tabular}{|c|c|c|c|c|c|c|c|c|}
\hline \multirow{3}{*}{$\begin{array}{l}\text { Intellectual } \\
\text { Standards and } \\
\text { Elements of } \\
\text { Thought }\end{array}$} & \multicolumn{5}{|c|}{ Paired Differences } & \multirow[t]{3}{*}{ t-test } & \multirow[t]{3}{*}{$\mathrm{df}$} & \multirow{3}{*}{$\begin{array}{l}\text { Sig. }(2 \\
\text { tailed) }\end{array}$} \\
\hline & \multirow[t]{2}{*}{ Mean } & \multirow[t]{2}{*}{$\begin{array}{c}\text { Std. } \\
\text { Deviation }\end{array}$} & \multirow[t]{2}{*}{$\begin{array}{l}\text { Std. } \\
\text { Error } \\
\text { Mean }\end{array}$} & \multicolumn{2}{|c|}{$\begin{array}{l}95 \% \text { Confidence } \\
\text { Interval of the } \\
\text { Difference }\end{array}$} & & & \\
\hline & & & & Lower & Upper & & & \\
\hline Clarity & -.800 & 1.517 & .277 & -1.366 & -.233 & -2.887 & 29 & .007 \\
\hline Accuracy & -.233 & 1.040 & .189 & -.621 & .155 & -1.229 & 29 & .229 \\
\hline Precision & .200 & 1.730 & .315 & -.446 & .846 & .633 & 29 & .532 \\
\hline Relevance & -.733 & 1.638 & .299 & -1.345 & -.121 & -2.451 & 29 & .021 \\
\hline Significance & -.466 & 1.525 & .278 & -1.036 & .102 & -1.676 & 29 & .105 \\
\hline Depth & -.266 & 1.529 & .279 & -.837 & .304 & -.955 & 29 & .348 \\
\hline Breadth & -.300 & .702 & .128 & -.562 & -.037 & -2.340 & 29 & .026 \\
\hline Logic & -.800 & 1.186 & .216 & -1.242 & -.357 & -3.694 & 29 & .001 \\
\hline Fairness & -.200 & 1.471 & .268 & -.749 & .349 & -.744 & 29 & .463 \\
\hline Purpose & -.166 & .949 & .173 & -.521 & .188 & -.961 & 29 & .344 \\
\hline Questions & -.600 & 1.191 & .217 & -1.045 & -.154 & -2.757 & 29 & .010 \\
\hline Information & -.533 & 1.357 & .247 & -1.040 & -.026 & -2.151 & 29 & .040 \\
\hline Inferences & -.366 & 1.629 & .297 & -.974 & .241 & -1.233 & 29 & .228 \\
\hline Concepts & .066 & 1.779 & .324 & -.597 & .731 & .205 & 29 & .839 \\
\hline Assumptions & .100 & 1.539 & 281 & -.474 & .674 & .356 & 29 & .725 \\
\hline Point of view & -.666 & 1.124 & .205 & -1.086 & -.246 & -3.247 & 29 & .003 \\
\hline Implications & .066 & 1.080 & .197 & -.336 & .470 & .338 & 29 & .738 \\
\hline
\end{tabular}

It was also necessary to use the independent t-test to identify the significance of the perceived improvement in participants' critical thinking skills between the two groups after the experiment (i.e. comparing only the post surveys for both groups). The results of independent t-tests for comparing mean values of the post surveys between the two groups showed that there were statistically significant differences (with $\mathrm{p}<0.05$ ) for the intervention group only in the Intellectual Standards: Clarity and in the Elements of Thought: Point of View, after the experiment was carried out. Thus, participants in the intervention groups had self-reported that they had improved in one Intellectual Standard and in one of the Elements of Thought. The data from the two-month mobile intervention from the thirty students in the intervention group were also analyzed. In general, there was a modest estimated correlation (with 0.65 ) between the total time spent on the mobile application and the total 
scores of the post-survey for each participant. However, there no correlation was found between time spent in a certain intervention component and its mapped Standards or Elements. As illustrated in Fig. 3, participants spent more time reading the content than typing in the mobile application. The results for the engagement with the mobile intervention showed that the amount of time spent in the mobile intervention by all participants varied depending on the specific intervention components: project information (66 minutes), first activity (136 minutes), second activity (96 minutes), third activity (115 minutes), first task ( 82 minutes), second task (97 minutes), third task (69 minutes), short quizzes (45 minutes), goals and plans (19 minutes), inquiries and answers (49 minutes), and feedback (92 minutes). The weekly notifications (feedback and reminders) by regularly nudging participants to participate helped to keep them engaged with the mobile application to practice critical thinking in research projects.

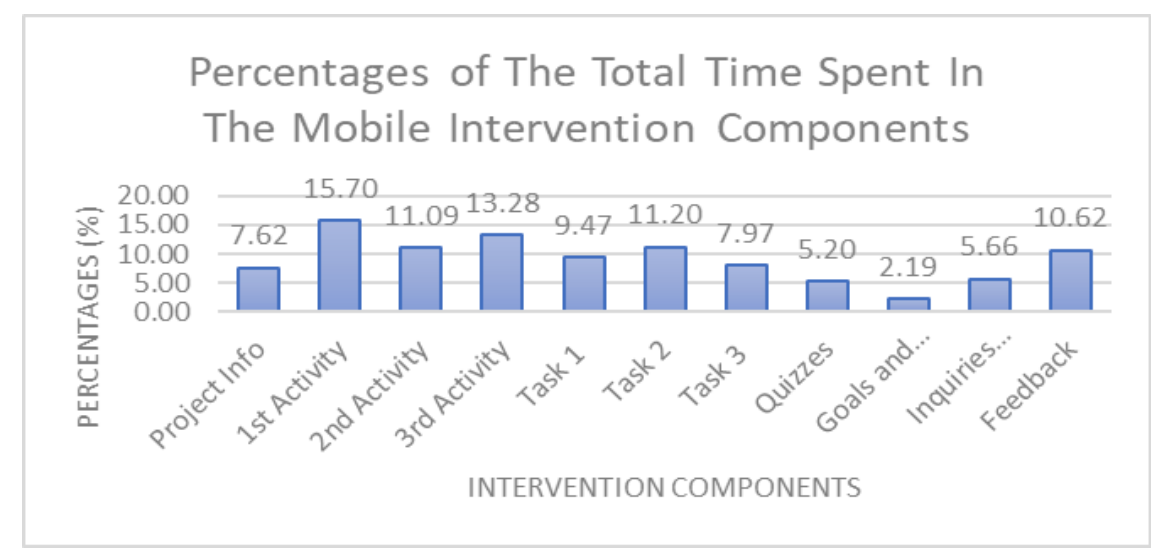

Figure 3. Engagement with the Mobile Intervention Components

Lastly, the usability of the mobile application as measured by the total mean of SUS scores for the current research was 77.3, is above the average score of 75.24 (Bangor et al., 2008) of usability in the area of mobile and web interfaces. This indicated that the mobile application-based intervention is useful and easy to use based on the calculated overall average of SUS scores.

\section{DISCUSSION, CONCLUSIONS AND FUTURE WORK}

In this study, the mobile behavior change intervention helped show perceived improvement in some critical thinking Standards and Elements for the participants who used the mobile components in the context of their research projects. The mobile intervention has effectively drawn students' attention into critical thinking while working on their research projects. However, the experiment took place during only the first two months of the students' research projects. This might be the reason for the improvement in some but not all Standards and Elements of critical thinking. The overall results indicated that students still need support in their critical thinking when working in research projects as reported in the literature as well by Al-Mubaid and Bettayeb (2017) and Asiri et al. (2017). As a limitation, the researcher was a replacement for the supervisors to support students' critical thinking with the feedback and answers for the students inquires during the experiment. This occurred because of the limited time and busy schedules for the academics in supervision during the semester. This may have introduced inaccuracies in outcomes. In future work, further assessment by experts and academics will be carried on for the qualitative data gathered from this experiment. More evaluation of the mobile $\log$ files to understand the effect of the mobile intervention components on the improvement in certain Standards and Elements of the critical thinking will be undertaken. To conclude, engaging with these mobile components helped students understand, practice, reflect and use critical thinking skills in their research projects. The mobile application with its components was deemed by participants to be practical, useful and easy to use. 


\section{REFERENCES}

Al-Mubaid H. and Bettayeb S., 2017. Intervention-Based Method for Improving Learning and Critical Thinking. Computing Conference. United Kingdom, London, pp. 1232-1237. IEEE.

Alnuaim, A., Caleb-Solly, P. and Perry, C., 2014. Evaluating the Effectiveness of a Mobile Location-Based Intervention for Improving Human-Computer Interaction Students' Understanding of Context for Design. International Journal of Mobile Human Computer Interaction (IJMHCI), 6(3), pp. 16-31.

Asiri, Y., Millard, D. and Weal, M., 2017. Digital Mobile-Based Behaviour Change Interventions to Assess and Promote Critical Thinking and Research Skills among Undergraduate Students. In Interactive Mobile Communication, Technologies and Learning. Thessaloniki, Greece, pp. 155-166. Springer, Cham.

Bangor, A., Kortum, P.T. and Miller, J.T., 2008. An Empirical Evaluation of the System Usability Scale. International Journal of Human-Computer Interaction, 24(6), pp. 574-594.

Brew, A. and Mantai, L., 2017. Academics' Perceptions of the Challenges and Barriers to Implementing Research-Based Experiences for Undergraduates. Teaching in Higher Education, 22(5), pp.551-568.

Brooke, J., 1996. SUS-A Quick and Dirty Usability Scale. Usability Evaluation in Industry, 189(194), pp.4-7.

Carpi, A., Ronan, D.M., Falconer, H.M. and Lents, N.H., 2017. Cultivating Minority Scientists: Undergraduate Research Increases Self-Efficacy and Career Ambitions for Underrepresented Students in STEM. Journal of Research in Science Teaching, 54(2), pp. 169-194.

Clear, T., 2014. Supervision for Critical Thinking: Challenges and Strategies. ACM Inroads, 5(4), pp. 26-27.

Cottrell, S., 2017. Critical Thinking Skills. Effective Analysis, Argument and Reflection. Palgrave Macmillan, New York, US.

Devi, V., Abraham, R.R. and Kamath, U., 2017. Teaching and Assessing Reflecting Skills among Undergraduate Medical Students Experiencing Research. Journal of clinical and diagnostic research: JCDR, 11(1), JC01-JC05.

Duron, R., Limbach, B. and Waugh, W., 2006. Critical Thinking Framework for any Discipline. International Journal of Teaching and Learning in Higher Education, 17(2), pp. 160-166.

Lustria, M.L.A., Noar, S.M., Cortese, J., Van Stee, S.K., Glueckauf, R.L. and Lee, J., 2013. A Meta-Analysis of Web-Delivered Tailored Health Behavior Change Interventions. Journal of Health Communication, 18(9), pp.1039-1069.

Haghparast, M., Nasaruddin, F.H. and Abdullah, N., 2014. Cultivating Critical Thinking through E-learning Environment and Tools: A Review. Procedia-Social and Behavioral Sciences, 129, pp.527-535.

Hargood, C., Michaelides, D., Weal, M., Pejovic, V., Musolesi, M., Morrison, L. and Yardley, L., 2014. The UBhave Framework: Developing Dynamic Mobile Applications for Digital Behavioural Interventions. In 11th International Conference on Mobile and Ubiquitous Systems: Computing, Networking and Services. London, United Kiddom (pp. 02-05).

Ismail, A., Masek, A., Hashim, S., Ismail, I.M., Ismail, M.E. and Amin, N.D.M., 2017. The Relationship between Student's Characteristic and Effective Supervision: The Case of Industrial-Based Project. In Engineering Education (ICEED), IEEE 9th International Conference. Kanazawa, Japan (pp. 132-136).

Paul, R. and Elder, L., 2013. Critical Thinking: Tools for Taking Charge of Your Professional and Personal Life. Pearson Education, London, United Kingdom.

Saade, R.G., Morin, D. and Thomas, J.D., 2012. Critical Thinking in E-learning Environments. Computers in Human Behavior, 28(5), pp. 1608-1617.

Seifi, H., Halbert, H. and McGrenere, J., 2014. Supervisor-Student Research Meetings: A Case Study on Choice of Tools and Practices in Computer Science. In Proceedings of Graphics Interface. Montreal, Canada (pp. 129-135).

Swart, R., 2017. Critical Thinking Instruction and Technology Enhanced Learning from the Student Perspective: A Mixed Methods Research Study. Nurse Education in Practice, 23, pp.30-39.

Wai, I.S.H., Ng, S.S.Y., Chiu, D.K., Ho, K.K. and Lo, P., 2018. Exploring Undergraduate Students' Usage Pattern of Mobile Apps for Education. Journal of Librarianship and Information Science, 50(1), pp. 34-47.

Wilde, A and Zaluska, E 2016. Held-by-hand Learners: A Survey of Technologies to Support Positive Behaviours of Higher Education Students Today. In R Roig-Vila (ed.), Tecnología, Innovación e Investigación en los Procesos de Enseñanza-Aprendizaje. Editorial Octaedro, Barcelona, Spain, pp. 3122-3132.

Wong Kung Fong, M., 2013. CritIQ: A Mobile Critique App for Undergraduate Communication Design Learners. Design and Culture, 5(3), pp.313-332.

Yardley, L., Choudhury, T., Patrick, K. and Michie, S., 2016. Current Issues and Future Directions for Research into Digital Behavior Change Interventions. American Journal of Preventive Medicine, 51(5), pp. 814-815.

Yilmaz, F.G.K. and Keser, H., 2016. The Impact of Reflective Thinking Activities in E-Learning: A Critical Review of the Empirical Research. Computers \& Education, 95, pp. 163-173. 